\title{
PENGARUH RAW MATERIALS COST DAN DIRECT LABOR COST TERHADAP COST OF PRODUCTION PADA UMKM DI KOTA BATAM
}

\author{
Baru Harahap \\ Fakultas Ilmu Sosial dan Humaniora, Universitas Putera Batam \\ baru@puterabatam.ac.id
}

\begin{abstract}
The purpose of this study was to find out whether the cost of raw materials and direct labor costs had an effect on the increase in production. In this quantitative research two types of variables are used, namely the independent variable is Raw Material Cost, Direct Labor Cost and the dependent variable is Increased Production Results. Sampling is done by the technique used, namely purposive sampling. Data analysis using Classical Assumptions and Multiple Linear Regression methods. The results of the study were processed using SPSS 20, it can be seen that the Raw Material Cost has a tcount of 4.616 with a significance probability of 0.000, concluded that Raw Material Costs partially have a positive and significant effect on Increasing Production Cost of Direct Labor Costs has t count of 4.944 with a significance of 0,000 can be concluded that Direct Labor Costs partially have a positive and significant effect on Increasing Production Results. The F test shows the Fcount value of 71,270 and significance of 0,000b means that there is a significant effect between Raw Material Costs and Direct Labor Costs on Increasing Production Results.
\end{abstract}

Keywords: Raw Material Costs, Direct labor costs, Increase in Production Results

\section{PENDAHULUAN}

Persaingan dunia usaha sekarang ini semakin besar, terutama usaha dalam sektor industri. Hal ini ditandai dengan banyak didirikannya usaha didaerahdaerah baik usaha kecil maupun usaha menengah. Pengusaha-pengusaha biasanya mendirikan usaha yang sejenis, karena termotivasi oleh pengusaha yang telah berhasil lebih dahulu memasuki dunia usaha. Hal tersebut menyebabkan persaingan antar pengusaha semakin ketat. Persaingan yang terjadi meliputi persaingan kualitas produk, harga, dan pemasaran. Persaingan antar pengusaha yang memproduksi barang atau jasa yang sama (homogen) biasanya terjadi dalam hal kualitas maupun harga. Hal tersebut merupakan ancaman bagi keberlangsungan usahanya. Langkah yang ditempuh yaitu dengan cara menyesuaikan dengan perubahan yang ada baik dari dalam maupun luar perusahaan dan mengelola faktor produksi yang ada dengan efektif dan efisien.

Pengembangan UKM perlu mendapatkan perhatian yang besar baik dari pemerintah maupun masyarakat agar dapat berkembang lebih kompetitif bersama pelaku ekonomi lainnya. Kebijakan pemerintah kedepan perlu diupayakan lebih kondusif bagi tumbuh dan berkembangnya UKM. Pemerintah perlu meningkatkan perannya dalam memberdayakan UKM disamping mengembangkan kemitraan usaha yang saling menguntungkan antara pengusaha besar dengan pengusaha kecil, dan meningkatkankualitas sumber daya manusianya (Kuncoro, 2013).

(Kuncoro, 2013) mengemukakan bahwa pengembangan industri kecil adalah cara yang dinilai besar peranannya dalam pengembangan industri manufaktur. Pengembangan industri berskala kecil akan membantu mengatasi masalah pengangguran mengingat teknologi yang digunakan adalah teknologi padat karya, sehingga bisa memperbesar lapangan kerja dan 
kesempatan usaha, yang pada gilirannya mendorong pembangunan daerah dan kawasan pedesaan.

Menurut (Nasution, 2013) jika faktor-faktor produksi yang digunakan oleh perusahaan dapat dikelola dengan baik dengan cara ekonomis, maka cost of production dapat ditingkatkan, biaya produksi menurun dan hal tersebut mempengaruhi pendapatan yang diterima dari hasil penjualan. Jika produksi perusahaan lancar, maka perusahaan memperoleh pendapatan yang optimal dari penjualan cost of production yang dilakukan oleh perusahaan.

\section{TINJAUAN PUSTAKA}

\section{A. Pengertian Produksi}

Kegiatan perusahaan manufaktur terdiri dari pengolahan bahan baku menjadi produk jadi dan penjualan produk jadi tersebut kepada konsumen atau perusahaan manufaktur lain. Kegiatan pengolahan bahan baku menjadi produk jadi tersebut memerlukan 3 (tiga) kelompok pengorbanan sumber ekonomi yaitu pengorbanan bahan baku, pengorbanan jasa tenaga kerja, dan pengorbanan jasa fasilitas (Mulyadi, 2013).

Pengolahan bahan baku menjadi produk jadi sering disebut dengan istilah produksi. Menurut (Nasution, 2014), produksi adalah proses kombinasi dan koordinasi material-material dan kekuatan-kekuatan (input, faktor sumber daya, atau jasa-jasa produksi) dalam pembuatan suatu barang atau jasa (output atau produk).

Sedangkan (Soeharno, 2015) mengemukakan bahwa produksi adalah kegiatan untuk meningkatkan manfaat dengan cara mengkombinasikan faktor produksi modal (capital) tenaga kerja, teknologi, dan managerial skill. Produksi merupakan usaha untuk meningkatkan manfaat dengan cara mengubah bentuk (form utility), memindahkan tempat (place utility), dan menyimpan (store utility).

\section{B. Hasil Produksi (Cost Of Production)}

Menurut (Haryanto, 2012), hasil produksi atau output adalah total barang atau jasa yang dihasilkan oleh unit usaha atau perusahaan. Hasil produksi merupakan keluaran (output) yang diperoleh dari pengelolaan input produksi (sarana produksi atau biasa disebut masukan) dari suatu usaha.

Sedangkan menurut (Beattie, 2014), produk sebagai output (keluaran) dari proses produksi sangat bergantung pada faktor produksi sebagai input (masukan). Semakin besar jumlah faktor produksi (input) yang masuk dalam proses produksi, semakin besar pula jumlah produk (output) yang dihasilkan.

\section{Biaya Bahan Baku (Raw Materials Cost)}

Menurut (Nafarin, 2014), bahan baku adalah bahan utama atau bahan pokok dan merupakan komponen utama dari suatu produk. Sedangkan menurut (Mulyadi, 2013), bahan baku merupakan bahan yang membentuk bagian menyeluruh produk jadi. Bahan baku yang diolah dalam perusahaan manufaktur dapat diperoleh dari pembelian lokal, impor atau pengolahan sendiri. Bahan baku merupakan bahan yang membentuk bagian menyeluruh produk jadi. Di dalam memperoleh bahan baku, perusahaan tidak hanya mengeluarkan biaya sejumlah harga beli saja, tetapi juga mengeluarkan biaya-biaya pembelian, pergudangan, dan biaya perolehan lainnya.

\section{Biaya Tenaga Kerja Langsung (Direct Labor Cost)}

Menurut (Sukirno, 2015), tenaga kerja dibedakan menjadi tiga golongan yaitu tenaga kerja kasar, tenaga kerja terampil dan tenaga kerja terdidik. Tenaga kerja kasar adalah tenaga kerja yang tidak berpendidikan atau rendah pendidikannya dan tidak memiliki keahlian dalam suatu bidang pekerjaan. Tenaga kerja terampil adalah tenaga kerja yang memiliki keahlian dari pelatihan atau pengalaman kerja. Sedangkan tenaga kerja tedidik adalah tanaga kerja yang memiliki pendidikan cukup tinggi dan ahli dalam bidang tertentu. 


\section{E. Kerangka Berfikir}

Kerangka pemikiran ialah penjelasan sementara terhadap gejala yang menjadi objek permasalah. Maka dari itu dapat dijelaskan bahwa objek permasalahan yang di angkat dalam penelitian ini ialah " Analisis Penerapan Akuntansi Raw Materials Cost Dan Direct Labor Cost Terhadap Cost Of Production Pada UMKM Bina Usaha Rakyat Di Kota Batam". Konsep yang telah dijelaskan tersebut dapat digambarkan seperti di bawah ini:

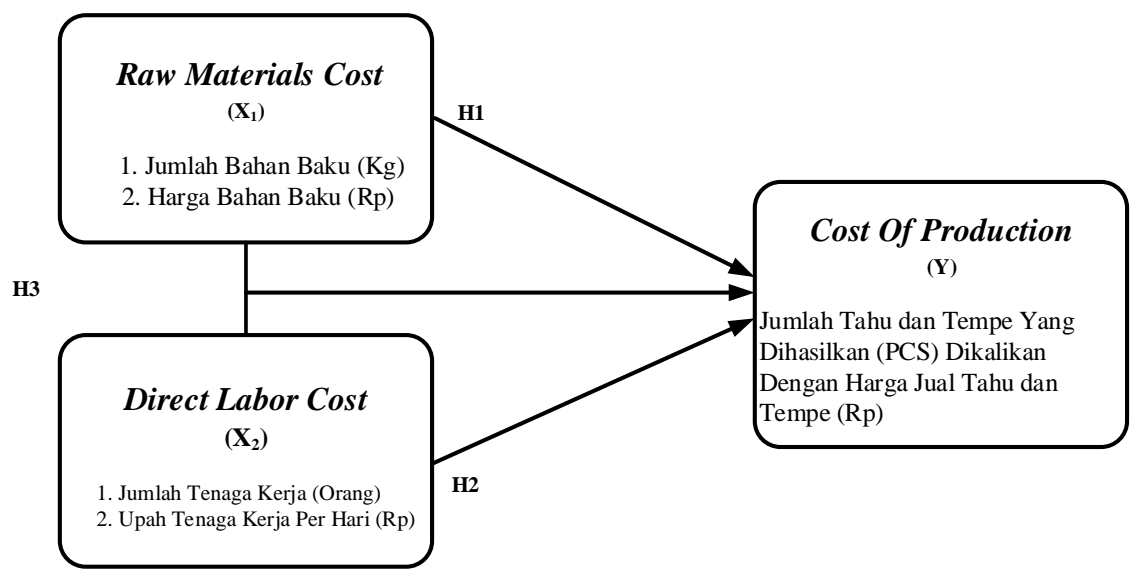

Gambar 1 Kerangka Pemikiran

\section{F. Hipotesis}

Hipotesis yang diajukan dalam penelitian ini sebagai berikut:

Hipotesis 1: Raw materials cost berpengaruh signifikan terhadap cost of production pada UMKM Bina Usaha Rakyat Di Kota Batam.

Hipotesis 2: Direct labor cost berpengaruh signifikan terhadap cost of production pada UMKM Bina Usaha Rakyat Di Kota Batam.

Hipotesis 4: Raw materials cost dan direct labor cost berpengaruh signifikan terhadap cost of production pada UMKM Bina Usaha Rakyat Di Kota Batam.

\section{METODE}

\section{A. Desain Penelitian}

Desain penelitian merupakan suatu rencana kerja yang terstruktur dalam hal hubunganhubungan antar variabel secara komprehensif, sedemkian rupa agar hasil risetnya dapat memberikan jawaban atas pertanyaan- pertanyaan riset. Dalam rencana tersebut mencakup halhal yang akan dilakukan periset mulai dari membuat hipotesis dan implikasinya secara operasional sampai pada analisis terakhir (Umar, 2017: 5).

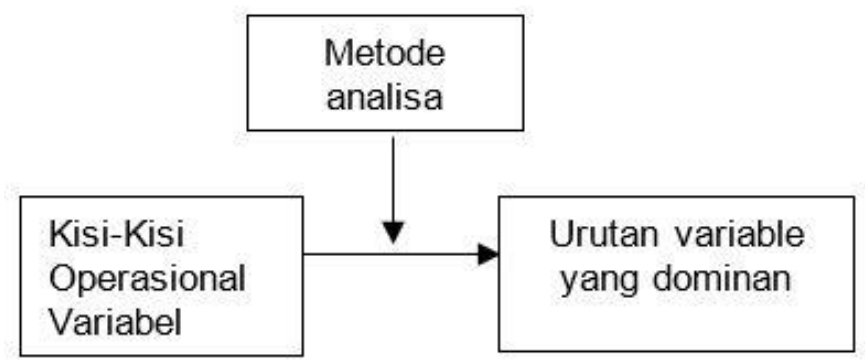

Gambar 2. Tahapan Penelitian

\section{B. Lokasi Penelitian}


Ketua Umum Koperasi Padjajaran Batam, Obos Bastaman mengatakan, pembangunan Sentra Tahu Tempe ini ditargetkan selesai dalam dua tahun ke depan. Pembangunan Sentra Tahu Tempe menurut Obos telah direncanakan sejak 12 tahun lalu. Namun, karena berbagai hal, pembangunan bisa dilaksanakan tahun ini. Pendirian Sentra Tahu Tempe merupakan upaya untuk menyatukan UMKM (Usaha Mikro Kecil dan Menengah), khususnya pembuat tahu dan tempe serta industri turunannya, seperti keripik dan sebagainya.

Mewujudkan Batam sebagai Sentra Tahu Tempe di Kepri, UMKM Bina Usaha Rakyat yang terletak di Perumahan Sari Padjajaran Tembesi, Kecamatan Sagulung yang menjadi objek penelitian penulis.

\section{Populasi dan Sampel}

Populasi dalam penelitian ini adalah UMKM Bina Usaha Rakyat. Menurut Dinas Perindustrian dan Perdagangan Kota Batam tahun 2019 jumlah perusahaan kecil industri Tahu Tempe di Sagulung yang masih aktif sebanyak 63 (enam puluh tiga) pengusaha, karena populasi kurang dari 100 maka seluruhnya akan dijadikan sampel sehingga penelitian ini bisa disebut sebagai sampel populasi.

\section{HASIL DAN PEMBAHASAN}

Hasil penelitian merupakan ringkasan dari informasi yang diperoleh dari data dan disajikan dari bentuk uji t dan uji f.

\section{Hasil Uji t}

Digunakan untuk mengetahui pengaruh variabel independen atau bebas (X) terhadap variabel dependen atau terikat (Y).

Tabel 3 Analisis Regresi Linier Berganda

Coefficients $^{\mathrm{a}}$

\begin{tabular}{|c|c|c|c|c|c|c|}
\hline \multirow{2}{*}{\multicolumn{2}{|c|}{ Model }} & \multicolumn{2}{|c|}{ Unstandardized Coefficients } & \multirow{2}{*}{$\begin{array}{c}\begin{array}{c}\text { Standardized } \\
\text { Coefficients }\end{array} \\
\text { Beta }\end{array}$} & \multirow[b]{2}{*}{$\mathrm{t}$} & \multirow[b]{2}{*}{ Sig. } \\
\hline & & B & Std. Error & & & \\
\hline \multirow[t]{3}{*}{1} & (Constant) & 13.933 & .501 & & 6.646 & .000 \\
\hline & Raw materials cost & 689 & .101 & .415 & 4.616 & .000 \\
\hline & Direct labor cost & .873 & .081 & .445 & 4.944 & .000 \\
\hline
\end{tabular}

a. Dependent Variable: Cost of production

Ada pun bentuk persamaan dari hasil perhitungan diatas adalah :

$$
Y=13.933+0.689 X_{1}+0.873 X_{2 .}+e
$$

\section{Konstan $=13.933$}

Nilai konstanta positif menunjukkan pengaruh positif, variabel $\mathrm{X}\left(\mathrm{X}_{1}\right.$ dan $\left.\mathrm{X}_{2}\right)$, bila variabel X (Raw materials cost dan Direct labor cost naik satu satuan, artinya variabel Cost of production (Y) akan mengalami kenaikan sebesar 13.933.

\section{Raw materials cost $\left(\mathrm{X}_{1}\right)=\mathbf{0 . 6 8 9}$}

Merupakan nilai koefisien regresi variabel Raw materials cost $\left(\mathrm{X}_{1}\right)$ terhadap variabel Cost of production (Y) artinya jika Raw materials cost naik satu satuan, maka Cost of production $(\mathrm{Y})$ akan mengalami peningkatan sebesar 0.689 . Koefisien bernilai positif artinya antara Raw materials cost $\left(\mathrm{X}_{1}\right)$ dan Cost of production $(\mathrm{Y})$ memiliki hubungan positif. Peningkatan nilai variable $\mathrm{X}_{1}$ akan mengakibatkan penurunan pada variable Cost of production (Y).

3. Direct labor cost $\left(\mathrm{X}_{2}\right)=\mathbf{0 . 8 7 3}$ 
Merupakan nilai koefisien regresi variabel independen Direct labor cost $\left(\mathrm{X}_{2}\right)$ terhadap variabel Cost of production (Y) artinya jika Direct labor cost $\left(\mathrm{X}_{2}\right)$ mengalami kenaikan satu satuan, maka Cost of production (Y) akan mengalami peningkatan sebesar 0.873. Koefisien bernilai positif artinya antara Direct labor cost $\left(\mathrm{X}_{2}\right)$ dan Cost of production (Y) memiliki hubungan positif. Peningkatan Direct labor cost $\left(\mathrm{X}_{2}\right)$ akan mengakibatkan peningkatan pada Cost of production $(\mathrm{Y})$.

Tabel 4 Uji $t$

\section{Coefficients $^{\mathrm{a}}$}

\begin{tabular}{|c|c|c|c|c|c|c|}
\hline \multirow{2}{*}{\multicolumn{2}{|c|}{ Model }} & \multicolumn{2}{|c|}{ Unstandardized Coefficients } & \multirow{2}{*}{$\begin{array}{c}\text { Standardized } \\
\text { Coefficients }\end{array}$} & \multirow[b]{2}{*}{$\mathrm{T}$} & \multirow[b]{2}{*}{ Sig. } \\
\hline & & B & Std. Error & & & \\
\hline \multirow[t]{3}{*}{1} & (Constant) & 13.933 & .501 & & 6.646 & .000 \\
\hline & Raw materials cost & .689 & .101 & .415 & 4.616 & .000 \\
\hline & Direct labor cost & .873 & .081 & .445 & 4.944 & .000 \\
\hline
\end{tabular}

a. Dependent Variable: Cost of production

Berdasarkan tabel 2 di atas dapat dilihat nilai Raw materials cost yang mempunyai nilai signifikan $0.000>0,05$. Artinya Raw materials cost berpengaruh signifikan terhadap Cost of production. Hal ini menunjukkan bahwa semakin besar perusahaan maka semakin besar sumber daya yang dimiliki oleh perusahaan tersebut untuk mengelola beban pajaknya.

Hasil perhitungan dari Direct labor cost mempunyai nilai signifikan $0.000>0,05$. Artinya Direct labor cost berpengaruh signifikan terhadap Cost of production. Hal ini berarti semakin besar hutang maka laba kena pajak akan menjadi lebih kecil karena insentif pajak atas bunga hutang yang semakin besar. Sehingga semakin tinggi Direct labor cost maka akan semakin rendah Cost of production yang dilakukan perusahaan karena timbulnya biaya bunga.

Tabel 5 Uji F

ANOVA $^{\text {b }}$

\begin{tabular}{|c|c|c|c|c|c|}
\hline Model & Sum of Squares & Df & Mean Square & $\mathrm{F}$ & Sig. \\
\hline 1 Regression & 905.705 & 2 & 234.160 & 71.270 & $.000^{b}$ \\
\hline Residual & 552.803 & 87 & 1.511 & & \\
\hline Total & 1458.508 & 89 & & & \\
\hline
\end{tabular}

a. Predictors: (Constant), Direct labor cost, Raw materials cost

b. Dependent Variable: Cost of production

Berdasarkan tabel Uji F diatas diperoleh nilai signifikan 0,000 $<0,05$ yang menunjukkan secara simultan Direct labor cost dan Raw materials cost, secara bersama-sama berpengaruh signifikan terhadap Cost of production (Y).

\section{SIMPULAN}

Berdasarkan hasil analisis data dan pembahasan mengenai Analisis tingkat efektifitas dan besar direct labor cost terhadap Cost of production yang telah diuraikan sebelumnya, dapat disimpulkan sebagai berikut:

1. Raw materials cost berpengaruh positif dan signifikan terhadap Cost of production UMKM Bina Usaha Rakyat Di Kota Batam.

2. Direct labor cost berpengaruh positif dan signifikan terhadap Cost of production UMKM

Bina Usaha Rakyat Di Kota Batam. 
3. Raw materials cost dan direct labor cost secara bersama-sama memiliki pengaruh yang positif dan signifikan terhadap Cost of production UMKM Bina Usaha Rakyat Di Kota Batam.

\section{SARAN} adalah:

Adapun rekomendasi yang dapat disarankan penulis untuk penelitian selanjutnya

1. UMKM Bina Usaha Rakyat Di Kota Batam harus memberikan perhatian lebih pada pengelolaan biaya produksi tidak boleh berlebih atau kurang. Biaya produksi yang berlebih dapat menurunkan kinerja keuangan perusahaan yang menyebabkan over investment yang justru akan menghambat perolehan keuntungan maksimal perusahaan. Sedangkan apabila terjadi kekurangan pada biaya produksi, maka kegiatan operasional perusahaan tidak dapat dibiayai sepenuhnya, sehingga sebaiknya perusahaan melakukan investasi asset perusahaan dengan kapasitas tepat.

2. Pengelolaan biaya produksi dan harga jual yang dilakukan UMKM Bina Usaha Rakyat Di Kota Batam pada periode 2015-2019 menunjukan angka yang baik, sekalipun terjadi penurunan namun ditiap satu periode keuangan perusahaan, Biaya Produksi dan Harga Jual perusahaan masih dapat menutupi 3 (tiga) kali perputaran aktifitas biaya produksi dan harga jualnya sendiri. Oleh sebab itu perusahaan wajib mempertahankan kinerja tersebut.

3. Untuk melengkapi hasil penelitian, maka sebaiknya dilakukan penelitian serupa dengan menambah sampel dan obyek penelitian yang lebih banyak agar memperoleh kesimpulan yang lebih lengkap dan dapat dipertanggungjawabkan.

\section{DAFTAR PUSTAKA}

Anwar, M. (2014). Factors Afecting Cotton Production in Pakistan: Empirical Evidence from Multan District. MPRA.No. 22829.91-100.

Arikunto, S. (2013). Prosedur Penelitian Suatu Pendekatan Praktik. Jakarta: Rineka Cipta.

Beattie, B. R. (2014). Ekonomi Produksi. Yogyakarta: Gajahmada University Press.

Kuncoro, M. (2013). Ekonomika Industri Indonesia (Menuju Negara Industri 2030). Yogyakarta: Andi Offset.

Kountur, R. (2013). Metode Penelitian untuk Penulisan Skripsi dan Tesis. Manajemen PPM, Jakarta.

Lasena, S. R. (2013). Analisis Penentuan Harga Pokok Produksi Pada PT. Dimembe Nyiur Agripro. Jurnal EMBA 585, Vol.1 No.3 Juni 2013, Hal. 585-592, ISSN 2303-1174.

Martono, N. (2012). Metode Penelitian Kuantitatif (Analisis Isi dan Analisis Data Sekunder) Edisi Revisi. PT. Raja Grafindo Persada. Jakarta.

Mulyadi. (2013). Akuntansi Biaya. Yogyakarta: Aditya Media.

Nasution, A. H. (2013). Manajemen Industri. Yogyakarta: Andi Offset.

Nafarin. (2014). Penganggaran Perusahaan. Jakarta: Salemba Empat.

Nazir, M. (2014). Metode Penelitian. Jakarta: Ghalia Indonesia.

Pinasih. (2015). Pengaruh Efisiensi Biaya Bahan Baku dan Efisiensi Biaya Tenaga Kerja terhadap Rasio profit Margin. Semarang: Fakultas Ekonomi UNNES.

Swastha, B \& Sukotjo, I. (2015). Pengantar Bisnis Modern. Yogyakarta: BPFE.

Samuelson, P. E. (2014). Ekonomi Industri. Yogyakarta: Betta Offset.

Sugiyono. (2013). Metode Penelitian Pendidikan: Pendekatan Kuantitatif, Kualitatif, dan R\&D. Bandung: Alfabeta.

Sugiarto, dkk. (2012). Ekonomi Mikro Sebuah Kajian Komprehensif. Jakarta: PT Gramedia Pustaka Utama.

Soeharno. (2015). Teori Mikro Ekonomi.Yogyakarta: Andi Offset.

Sukirno, S. (2015). Mikro Ekonomi Teori Pengantar. Jakarta: PT Raja Grafindo Persada.

Supriyono. R. A. (2013). Akuntansi Biaya. Yogyakarta : BPEE.

Umar, H. (2011). Metodologi Penelitian Untuk Skripsi dan Tesis Bisnis. Jakarta: PT. Gramedia Pustaka. 
Wilson, B. (2016). Teori Ekonomi Mikro. Bandung: Refika Aditama.

Wibowo, A. E . (2012). Aplikasi Praktis Spss Dalam Penelitian. Yogyakarta: Gava Media. 